\title{
Weakly Compatible Maps in Complex Valued G- Metric Spaces
}

\author{
S. Mudgal \\ Department of Mathematics \\ Echelon Institute of Technology \\ Jasana, Faridabad:121101, India
}

\begin{abstract}
In this paper, we introduce the notion of complex valued Gmetric spaces and prove a common fixed point theorem for weakly compatible maps in this newly defined spaces.
\end{abstract}

Mathematics Subject Classification (2000): 47H10, 54H 25 .

\section{Keywords}

Complex valued G-metric space, weakly compatible.

\section{INTRODUCTION}

The study of fixed points of mappings satisfying certain contractive conditions have been at the center of rigorous research activity. Recently, Mustafa and Sims [8,9] have shown that most of the results concerning Dhage's D-metric spaces are invalid, therefore they introduced an improved version of the generalized metric space structure which they called G-metric spaces.

In 2006, Mustafa and Sims [9] introduced the concept of Gmetric spaces as follows:

Definition 1.1. Let $X$ be a non-empty set, and let G: $X \times X \times X \rightarrow \mathbb{R}^{+}$be a function satisfying the following properties:

(G1) $\mathrm{G}(\mathrm{x}, \mathrm{y}, \mathrm{z})=0$ if $\mathrm{x}=\mathrm{y}=\mathrm{z}$,

(G2) $0<\mathrm{G}(\mathrm{x}, \mathrm{y}, \mathrm{z})$ for all $\mathrm{x}, \mathrm{y} \in \mathrm{X}$ with $\mathrm{x} \neq \mathrm{y}$,

(G3) $G(x, x, y) \leq G(x, y, z)$ for all $x, y, z \in X$ with $y \neq z$,

(G4) $\mathrm{G}(\mathrm{x}, \mathrm{y}, \mathrm{z})=\mathrm{G}(\mathrm{x}, \mathrm{z}, \mathrm{y})=\mathrm{G}(\mathrm{y}, \mathrm{z}, \mathrm{x})=\ldots$ (symmetry in all three variables ), (G5) $\mathrm{G}(\mathrm{x}, \mathrm{y}, \mathrm{z}) \leq \mathrm{G}(\mathrm{x}, \mathrm{a}, \mathrm{a})+$ $\mathrm{G}(\mathrm{a}, \mathrm{y}, \mathrm{z})$ for all $\mathrm{x}, \mathrm{y}, \mathrm{z}, \mathrm{a} \in \mathrm{X}$ (rectangle inequality).

Then the function $G$ is called a generalized metric or, more specially a G-metric on $\mathrm{X}$, and the pair $(\mathrm{X}, \mathrm{G})$ is called a G- metric space.

The idea of complex metric space was initiated by Azam et.al.[1] to exploit the idea of complex valued normed spaces and complex valued Hilbert spaces.

Definition 1.2. Let $\mathbb{C}$ be the set of complex numbers and $z_{1}, z_{2}$ $\in \mathbb{C}$. Define a partial order $\lesssim$ on $\mathbb{C}$ as follows: $\left(z_{2}\right)$

$z_{1} \lesssim z_{2}$ if and only if $\operatorname{Re}\left(z_{1}\right) \leq \operatorname{Re}\left(z_{2}\right)$ and $\operatorname{Im}\left(z_{1}\right) \leq \operatorname{Im}$

That is $z_{1} \precsim z_{2}$ if one of the following holds

(C1): $\operatorname{Re}\left(z_{1}\right)=\operatorname{Re}\left(z_{2}\right)$ and $\operatorname{Im}\left(z_{1}\right)=\operatorname{Im}\left(z_{2}\right)$
(C2): $\operatorname{Re}\left(z_{1}\right)<\operatorname{Re}\left(z_{2}\right)$ and $\operatorname{Im}\left(z_{1}\right)=\operatorname{Im}\left(z_{2}\right)$

(C3): $\operatorname{Re}\left(z_{1}\right)=\operatorname{Re}\left(z_{2}\right)$ and $\operatorname{Im}\left(z_{1}\right)<\operatorname{Im}\left(z_{2}\right)$

(C4): $\operatorname{Re}\left(z_{1}\right)<\operatorname{Re}\left(z_{2}\right)$ and $\operatorname{Im}\left(z_{1}\right)<\operatorname{Im}\left(z_{2}\right)$

In particular, we will write $z_{1} \lessgtr z_{2}$ if $z_{1} \neq z_{2}$ and one of (C2), (C3) and (C4) is satisfied and we will write $z_{1} \prec z_{2}$ if only (C4) is satisfied.

Remark 1.3. We obtained that the following statements hold:

(i) $\mathrm{a}, \mathrm{b} \in \mathrm{R}$ and $\mathrm{a} \leq \mathrm{b} \Rightarrow \mathrm{az} \lesssim \mathrm{bz}$ for all $\mathrm{z} \in \mathbb{C}$

(ii) $0 \precsim z_{1} \lessgtr z_{2} \Rightarrow\left|z_{1}\right|<\left|z_{2}\right|$

(iii) $z_{1} \precsim z_{2}$ and $z_{2} \prec z_{3} \Rightarrow z_{1} \prec z_{3}$.

Now we introduce the notion of complex valued G-metric space akin to the notion of complex valued metric spaces [1] as follows:

Definition 1.4. Let $\mathrm{X}$ be a non-empty set. Let $\mathrm{G}: X \times X \times$ $X \rightarrow \mathbb{C}$ be a function satisfying the following properties:

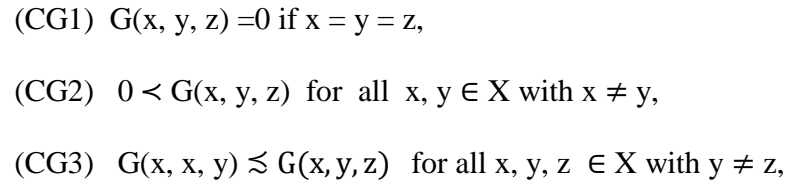
in all three variables ) (CG5) $\mathrm{G}(\mathrm{x}, \mathrm{y}, \mathrm{z}) \lesssim \mathrm{G}(\mathrm{x}, \mathrm{a}, \mathrm{a})+$ $\mathrm{G}(\mathrm{a}, \mathrm{y}, \mathrm{z})$ for all $\mathrm{x}, \mathrm{y}, \mathrm{z}, \mathrm{a} \in \mathrm{X}$.

Then the function $G$ is called a complex valued generalized metric or more specially, a complex valued G-metric on X, and the pair $(\mathrm{X}, \mathrm{G})$ is called a complex valued $\mathrm{G}$ - metric space.

\section{THE COMPLEX VALUED G- METRIC TOPOLOGY}

A point $x \in X$ is called interior point of a set $A \subseteq X$, whenever there exists $0 \prec r \in \mathbb{C}$ such that

$$
\mathrm{B}_{\mathrm{G}}(\mathrm{x}, \mathrm{r})=\{\mathrm{y} \in \mathrm{X}: \mathrm{G}(\mathrm{x}, \mathrm{y}, \mathrm{y}) \prec \mathrm{r}\} \subseteq \mathrm{A} .
$$

A point $\mathrm{x} \in \mathrm{X}$ is called limit point of a set $\mathrm{A}$ whenever there exists $0 \prec r \in \mathbb{C}$,

$$
\mathrm{B}_{\mathrm{G}}(\mathrm{x}, \mathrm{r}) \cap(\mathrm{A} / \mathrm{X}) \neq \varnothing .
$$


A is called open whenever each element of A is an interior point of $\mathrm{A}$. A subset $\mathrm{B} \subseteq \mathrm{X}$ is called closed whenever each limit point of $\mathrm{B}$ belongs to $\mathrm{B}$.

Proposition 2.1. Let $(\mathrm{X}, \mathrm{G})$ be complex valued G-metric space, then for any $x_{0} \in X$ and $r>0$, we have

$$
\begin{aligned}
& \text { (1) If } \mathrm{G}\left(x_{0}, x, y\right) \prec r \text {, then } x, y \in B_{G}\left(x_{0}, r\right) \\
& \text { (2) If } y \in B_{G}\left(x_{0}, r\right) \text {, then there exists } a \delta> \\
& 0 \text { such that } B_{G}(y, \delta) \subseteq B_{G}\left(x_{0}, r\right) \text {. }
\end{aligned}
$$

Proposition 2.2 Let $(\mathrm{X}, \mathrm{G})$ be complex valued G-metric space, then for all $\mathrm{x}_{0} \in \mathrm{X}$ and $\mathrm{r}>0$, we have,

$$
B_{G}\left(x_{0}, \frac{1}{3} r\right) \subseteq B_{d_{G}}\left(x_{0}, r\right) \subseteq B_{G}\left(x_{0}, r\right) .
$$

Where $d_{G}(x, y)=G(x, y, y)+G(x, x, y)$.

\section{CONVERGENCE, CONTINUITY AND COMPLETENESS IN COMPLEX VALUED G-METRIC SPACES}

Definition 3.1. Let $(X, G)$ be a complex valued G-metric space, let $\left\{x_{n}\right\}$ be a sequence of points of $X$, we say that $\left\{x_{n}\right\}$ is complex valued G-convergent to $\mathrm{x}$ if for any $\epsilon>0$, there exists $\mathrm{k} \in N$ such that $G\left(x, x_{n}, x_{m}\right) \prec \epsilon$, for all $\mathrm{n}, \mathrm{m} \geq \mathrm{k}$. We refer to $\mathrm{x}$ as the limit of the sequence $\left\{x_{n}\right\}$ and we write $x_{n} \stackrel{(G)}{\rightarrow} \mathrm{x}$.

Proposition 3.1. Let $(\mathrm{X}, \mathrm{G})$ be complex valued G-metric space, then for a sequence $\left\{x_{n}\right\} \subseteq X$ and point $\mathrm{x} \in \mathrm{X}$, the following are equivalent:

$$
\begin{aligned}
& \text { (1) }\left\{x_{n}\right\} \text { is complex valued } G- \\
& \text { convergent to } x \\
& \text { (2) }\left|G\left(x_{n}, x_{n}, x\right)\right| \rightarrow 0 \text { as } \mathrm{n} \rightarrow \infty \\
& \text { (3) }\left|G\left(x_{n}, x, x\right)\right| \rightarrow 0 \text { as } \mathrm{n} \rightarrow \infty \\
& \text { (4) }\left|G\left(x_{m}, x_{n}, x\right)\right| \rightarrow 0 \text { as } \mathrm{n}, m \rightarrow \infty
\end{aligned}
$$

Definition 3.2. Let $(X, G)$ and $\left(X^{\prime}, G^{\prime}\right)$ be two complex valued G-metric spaces. Then a function $\mathrm{f}: \mathrm{X} \rightarrow X^{\prime}$ is complex valued G-continuous at a point $\mathrm{x}_{0} \in \mathrm{X}$ if $f^{-1}\left(B_{G^{\prime}}\left(f\left(x_{0}\right), r\right)\right) \in \tau(G)$, for all $\mathrm{r}>0$. We say $\mathrm{f}$ is complex valued G-continuous if it complex valued Gcontinuous at all points of $\mathrm{X}$; that is, continuous as a function from $\mathrm{X}$ with the $\tau(G)$ - topology to $X^{\prime}$ with $\tau\left(G^{\prime}\right)$ - topology.

Since complex valued G-metric topologies are metric topologies we have:

Proposition 3.2. Let $(\mathrm{X}, \mathrm{G})$ and $\left(X^{\prime}, G^{\prime}\right)$ be two complex valued $\mathrm{G}$-metric spaces. Then a function $\mathrm{f}: \mathrm{X} \rightarrow X^{\prime}$ is complex valued $\mathrm{G}$-continuous at a point $\mathrm{x} \in \mathrm{X}$ if and only if it is complex valued G-sequentially continuous at $\mathrm{x}$ : that is whenever $\left\{x_{n}\right\}$ is complex valued $\mathrm{G}$-convergent to $\mathrm{x}$ we have ( $\left.\left\{x_{n}\right\}\right)$ is complex valued G-convergent to $\mathrm{f}(\mathrm{x})$.

Proposition 3.3. Let $(X, G)$ be a complex valued G-metric spaces, then the function $\mathrm{G}(\mathrm{x}, \mathrm{y}, \mathrm{z})$ is jointly continuous in all three of its variables.
Proof. Suppose $\left\{x_{k}\right\},\left\{y_{m}\right\}$, and $\left\{z_{n}\right\}$, are complex valued Gconvergent to $\mathrm{x}, \mathrm{y}$ and $\mathrm{z}$ respectively. Then, by (CG5) we have,

$$
\begin{aligned}
& \mathrm{G}(\mathrm{x}, \mathrm{y}, \mathrm{z}) \lesssim \mathrm{G}\left(\mathrm{y}, \mathrm{y}_{\mathrm{m}}, \mathrm{y}_{\mathrm{m}}\right)+\mathrm{G}\left(\mathrm{y}_{\mathrm{m}}, \mathrm{x}, \mathrm{z}\right) \\
& \mathrm{G}\left(\mathrm{z}, \mathrm{x}, \mathrm{y}_{\mathrm{m}}\right) \lesssim \mathrm{G}\left(\mathrm{x}, \mathrm{x}_{\mathrm{k}}, \mathrm{x}_{\mathrm{k}}\right)+\mathrm{G}\left(\mathrm{x}_{\mathrm{k}}, \mathrm{y}_{\mathrm{m}}, \mathrm{z}\right)
\end{aligned}
$$

and

$\mathrm{G}\left(\mathrm{z}, \mathrm{x}_{\mathrm{k}}, \mathrm{y}_{\mathrm{m}}\right) \lesssim \mathrm{G}\left(\mathrm{z}, \mathrm{z}_{\mathrm{n}}, \mathrm{z}_{\mathrm{n}}\right)+\mathrm{G}\left(\mathrm{z}_{\mathrm{n}}, \mathrm{y}_{\mathrm{m}}, \mathrm{x}_{\mathrm{k}}\right)$,

so,

$G(x, y, z)-G\left(x_{k}, y_{m}, z_{n}\right) \precsim G\left(y, y_{m}, y_{m}\right)+G\left(x, x_{k}, x_{k}\right)+$ $\mathrm{G}\left(\mathrm{z}, \mathrm{z}_{\mathrm{n}}, \mathrm{z}_{\mathrm{n}}\right)$.

Similarly,

$$
\begin{aligned}
& \mathrm{G}\left(\mathrm{x}_{\mathrm{k}}, \mathrm{y}_{\mathrm{m}}, \mathrm{z}_{\mathrm{n}}\right)-\mathrm{G}(\mathrm{x}, \mathrm{y}, \mathrm{z}) \quad \\
& \mathrm{G}\left(\mathrm{y}_{\mathrm{m}}, \mathrm{y}, \mathrm{y}\right)+\mathrm{G}\left(\mathrm{z}_{\mathrm{n}}, \mathrm{z}, \mathrm{z}\right) .
\end{aligned}
$$

But then combining these using (3) of proposition 4.1 we have,

$\left|G\left(x_{k}, y_{m}, z_{n}\right)-G(x, y, z)\right| \leq 2\left(G\left(x, x_{k}, x_{k}\right)+G\left(y, y_{m}, y_{m}\right)+\right.$ $\left.\mathrm{G}\left(\mathrm{z}, \mathrm{z}_{\mathrm{n}}, \mathrm{z}_{\mathrm{n}}\right)\right)$,

$\left|\mathrm{G}\left(\mathrm{x}_{\mathrm{k}}, \mathrm{y}_{\mathrm{m}}, \mathrm{z}_{\mathrm{n}}\right)-\mathrm{G}(\mathrm{x}, \mathrm{y}, \mathrm{z})\right| \rightarrow 0$, as $\mathrm{k}, \mathrm{m}, \mathrm{n}, \rightarrow \infty$ and the result follows by proposition 3.2.

Definition 3.2. Let $(X, G)$ be a complex valued G-metric space, a sequence $\left\{x_{n}\right\}$ is complex valued G- Cauchy if given $\epsilon>0$, there exists $\mathrm{k} \in N$ such that $G\left(x_{n}, x_{m}, x_{l}\right) \prec \epsilon$ for all $\mathrm{n}$, $\mathrm{m}, l \geq \mathrm{k}$.

Definition 3.3. A complex valued G-metric space $(X, G)$ is said to be complex valued G-complete if every complex valued G-Cauchy sequence is complex valued G-convergent in $(\mathrm{X}, \mathrm{G})$.

Proposition 3.4. Let $(\mathrm{X}, \mathrm{G})$ be a complex valued G-metric space. Then the following are equivalent:

(1) The sequence $\left\{x_{n}\right\}$ is a complex valued G-Cauchy in $\mathrm{X}$

(2) For every $\epsilon>0$, there exists $\mathrm{k} \in N$ such that $G\left(x_{n}, x_{m}, x_{m}\right) \prec \epsilon$, for all $\mathrm{n}, \mathrm{m} \geq \mathrm{k}$.

(3) $\left\{x_{n}\right\}$ is a Cauchy sequence in the complex valued metric space $(\mathrm{X}$, $\left.d_{G}\right)$.

Proposition 3.5. Let $(\mathrm{X}, \mathrm{G})$ be a complex valued G-metric space and $\left\{x_{n}\right\}$ be a sequence in $\mathrm{X}$. Then $\left\{x_{n}\right\}$ is complex valued $\mathrm{G}$ - convergent to $\mathrm{x}$ if and only if $\left|G\left(x, x_{n}, x_{m}\right)\right| \rightarrow 0$ as $\mathrm{n}, \mathrm{m} \rightarrow \infty$.

Proof. Suppose that $\left\{x_{n}\right\}$ is complex valued G- convergent to $\mathrm{x}$. For a given real number $\epsilon>0$, let

$$
\mathrm{c}=\frac{\epsilon}{\sqrt{2}}+i \frac{\epsilon}{\sqrt{2}} .
$$

Then $0 \prec \mathrm{r} \in \mathbb{C}$ and there is a natural number $\mathrm{k}$, such that $G\left(x, x_{n}, x_{m}\right) \prec \epsilon$ for all $\mathrm{n}, \mathrm{m} \geq \mathrm{k}$. 
Therefore,

$$
\left|G\left(x, x_{n}, x_{m}\right)\right|<|c|=\epsilon \text { for all } \mathrm{n}, \mathrm{m} \geq \mathrm{k} .
$$

It follows that $\left|G\left(x, x_{n}, x_{m}\right)\right| \rightarrow 0$ as $\mathrm{n}, \mathrm{m} \rightarrow \infty$.

Conversely, suppose that $\left|G\left(x, x_{n}, x_{m}\right)\right| \rightarrow 0$ as $\mathrm{n}, \mathrm{m} \rightarrow \infty$. Then given $\mathrm{r} \in \mathbb{C}$ with $0 \prec \mathrm{c}$, there exists a real number $\delta>0$, such that for $\mathrm{z} \in \mathbb{C}$

$$
|z|<\delta \Rightarrow \mathrm{z} \prec \mathrm{c} .
$$

For this $\delta$, there is a natural number k such that

$$
\left|G\left(x, x_{n}, x_{m}\right)\right|<\delta \text { for all } \mathrm{n}, \mathrm{m} \geq \mathrm{k} .
$$

This means that $G\left(x, x_{n}, x_{m}\right) \prec \epsilon$ for all $\mathrm{n}, \mathrm{m} \geq \mathrm{k}$. Hence $\left\{x_{n}\right\}$ is complex valued $\mathrm{G}$ - convergent to $\mathrm{x}$.

Proposition 3.6. Let $(\mathrm{X}, \mathrm{G})$ be a complex valued G-metric space and $\left\{x_{n}\right\}$ be a sequence in $\mathrm{X}$. Then $\left\{x_{n}\right\}$ is complex valued G- Cauchy sequence if and only if $\left|G\left(x_{n}, x_{m}, x_{l}\right)\right| \rightarrow 0$ as $\mathrm{n}, \mathrm{m} \rightarrow \infty$.

Proof. Suppose that $\left\{x_{n}\right\}$ is complex valued G- Cauchy sequence. For a given real number $\epsilon>0$, let

$$
\mathrm{c}=\frac{\epsilon}{\sqrt{2}}+i \frac{\epsilon}{\sqrt{2}} \text {. }
$$

Then $0 \prec \mathrm{r} \in \mathbb{C}$ and there is a natural number $\mathrm{k}$, such that $G\left(x_{n}, x_{m}, x_{l}\right) \prec \epsilon$ for all $\mathrm{n}, \mathrm{m} \geq \mathrm{k}$.

Therefore,

$$
\left|G\left(x_{n}, x_{m}, x_{l}\right)\right|<|c|=\epsilon \text { for all } \mathrm{n}, \mathrm{m} \geq \mathrm{k} .
$$

It follows that $\left|G\left(x_{n}, x_{m}, x_{l}\right)\right| \rightarrow 0$ as $\mathrm{n}, \mathrm{m} \rightarrow \infty$.

Conversely, suppose that $\left|G\left(x_{n}, x_{m}, x_{l}\right)\right| \rightarrow 0$ as $\mathrm{n}, \mathrm{m} \rightarrow \infty$. Then given $\mathrm{c} \in \mathbb{C}$ with $0 \prec \mathrm{c}$, there exists a real number $\delta>0$, such that for $\mathrm{z} \in \mathbb{C}$

$$
|z|<\delta \Rightarrow \mathrm{z} \prec \mathrm{c} .
$$

For this $\delta$, there is a natural number $\mathrm{k}$ such that

$$
\left|G\left(x_{n}, x_{m}, x_{l}\right)\right|<\delta \text { for all } \mathrm{n}, \mathrm{m} \geq \mathrm{k} \text {. }
$$

This means that $G\left(x_{n}, x_{m}, x_{l}\right) \prec \epsilon$ for all $\mathrm{n}, \mathrm{m} \geq \mathrm{k}$. Hence $\left\{x_{n}\right\}$ is complex valued G- Cauchy sequence.

\section{PROPERTIES OF COMPLEX VALUED G-METRIC SPACES}

Proposition 4.1. Let $(\mathrm{X}, \mathrm{G})$ be a complex valued G-metric space. Then for any $\mathrm{x}, \mathrm{y}, \mathrm{z}, \mathrm{a}$ in $\mathrm{X}$ it follows that:

$$
\begin{aligned}
& \text { (i) } \text { If } G(x, y, z)=0 \text { if } x=y=z \\
& \text { (ii) } G(x, y, \quad z) \quad \precsim G(x, x, y)+ \\
& \text { (iii) } G(x, x, z) \\
& \text { (iv) } G(x, y, y) \lesssim 2 G(y, x, x) \\
& \quad G(a, y, z)
\end{aligned}
$$

(v) $\quad \mathrm{G}(\mathrm{x}, \mathrm{y}, \mathrm{z}) \lesssim 2 / 3(\mathrm{G}(\mathrm{x}, \mathrm{y}, \mathrm{a})+$ $\mathrm{G}(\mathrm{x}, \mathrm{a}, \mathrm{z})+\mathrm{G}(\mathrm{a}, \mathrm{y}, \mathrm{z}))$

(vi) $\quad \mathrm{G}(\mathrm{x}, \quad \mathrm{y}, \quad \mathrm{z}) \quad(\mathrm{G}(\mathrm{x}, \mathrm{a}, \mathrm{a})+$ $\mathrm{G}(\mathrm{y}, \mathrm{a}, \mathrm{a})+\mathrm{G}(\mathrm{z}, \mathrm{a}, \mathrm{a}))$.

Proposition 4.2. Let $(\mathrm{X}, \mathrm{G})$ be a complex valued G-metric space. Then the following are equivalent:

(i) $\quad(\mathrm{X}, \mathrm{G})$ is symmetric.

(ii) $\quad G(x, y, y) \precsim G(x, y, a)$, for all $\mathrm{x}, \mathrm{y}, \mathrm{a} \in \mathrm{X}$.

(iii) $\mathrm{G}(\mathrm{x}, \mathrm{y}, \mathrm{z}) \lesssim \mathrm{G}(\mathrm{x}, \mathrm{y}, \mathrm{a})+\mathrm{G}(\mathrm{z}, \mathrm{y}, \mathrm{b})$ for all $\mathrm{x}$, $y, a, b \in X$.

In 1998, Jungck [7] introduced the concept of weakly compatibility as follows:

Definition 4.3 Two self mappings $S$ and $T$ are said to be weakly compatible if they commute at their coincidence points.

\section{MAIN RESULT}

Now we prove our main result for a pair of self mappings:

Theorem 5.1. Let $(\mathrm{X}, \mathrm{G})$ be a complete complex valued $\mathrm{G}$ metric space. Let $S, T: X \rightarrow X$ be self mappings satisfying the following conditions:

$$
\text { (2.1) } \mathrm{S}(\mathrm{X}) \subseteq \mathrm{T}(\mathrm{X}) \text {, }
$$

(2.2) any one of the subspace $\mathrm{S}(\mathrm{X})$ or $\mathrm{T}(\mathrm{X})$ is complete,

(2.3) $\mathrm{G}(\mathrm{Sx}, \mathrm{Sy}, \mathrm{Sz}) \precsim \mathrm{k} \mathrm{G}(\mathrm{Tx}, \mathrm{Ty}, \mathrm{Tz})$ for all $\mathrm{x}, \mathrm{y}, \mathrm{z}$ $\in X$, where $0 \leq \mathrm{k}<1$,

(2.4) S and T are weakly compatible self maps.

Then $\mathrm{S}$ and $\mathrm{T}$ have a unique common fixed point in $\mathrm{X}$.

Proof. Let $x_{0} \in \mathrm{X}$ be an arbitrary point in X. By (2.1), one can choose a point $x_{1}$ in $\mathrm{X}$ such that $\mathrm{S} x_{0}=T x_{1}$. In general choose $x_{n+1}$ such that

$$
y_{n}=S x_{n}=T x_{n+1} .
$$

Now, we prove $\left\{y_{n}\right\}$ is a complex valued G- Cauchy sequence in $\mathrm{X}$.

Putting $\mathrm{x}=x_{n}, \mathrm{y}=x_{n+1}, \mathrm{z}=x_{n+1}$ in (2.1), we have

$\mathrm{G}\left(S x_{n}, S x_{n+1}, S x_{n+1}\right) \lesssim \mathrm{kG}\left(T x_{n}, T x_{n+1}, T x_{n+1}\right)=\mathrm{kG}($

$\left.S x_{n-1}, S x_{n}, S x_{n}\right)$

Continuing in the same way, we have

$\mathrm{G}\left(S x_{n}, S x_{n+1}, S x_{n+1}\right) \lesssim k^{n} \mathrm{G}\left(S x_{0}, S x_{1}, S x_{1}\right)$

This implies that $\mathrm{G}\left(y_{n}, y_{n+1}, y_{n+1}\right) \lesssim k^{n} \mathrm{G}\left(y_{0}, y_{1}, y_{1}\right)$

Then, for all $\mathrm{n}, \mathrm{m} \in \mathrm{N}, \mathrm{n}<\mathrm{m}$, we have by (CG5)

$\mathrm{G}\left(y_{n}, y_{m}, y_{m}\right) \lesssim \mathrm{G}\left(y_{n}, y_{n+1}, y_{n+1}\right)+\mathrm{G}\left(y_{n+1}, y_{n+2}, y_{n+2}+\right.$ $\mathrm{G}\left(y_{n+2}, y_{n+3}, y_{n+3}\right)+\ldots+\mathrm{G}\left(y_{m-1}, y_{m}, y_{m}\right) \lesssim\left(k^{n}+\right.$ 
$\left.k^{n+1}+k^{n+2}+\cdots+k^{m-1}\right) \mathrm{G}\left(y_{0}, y_{1}, y_{1}\right) \quad \precsim \frac{k^{n}}{1-k} \mathrm{G}$

$\left(y_{0}, y_{1}, y_{1}\right)$,

Therefore,

$$
\left|\mathrm{G}\left(y_{n}, y_{m}, y_{m}\right)\right| \leq\left(\frac{k^{n}}{1-k}\right)\left|\mathrm{G}\left(y_{0}, y_{1}, y_{1}\right)\right|
$$

Since $k \in[0,1]$, if we taking limit as $\mathrm{n}, \mathrm{m} \rightarrow \infty$, then $\frac{k^{n}}{1-k}$ $\left|\mathrm{G}\left(y_{0}, y_{1}, y_{1}\right)\right| \rightarrow 0$,

i.e., $\mathrm{G}\left(y_{0}, y_{1}, y_{1}\right) \rightarrow 0$

For $\mathrm{n}, \mathrm{m}, l \in \mathrm{N}$ (CG5) implies that

$\mathrm{G}\left(y_{n}, y_{m}, y_{l}\right) \lesssim \mathrm{G}\left(y_{n}, y_{m}, y_{m}\right)+\mathrm{G}\left(y_{l}, y_{m}, y_{m}\right)$,

Therefore, $\quad\left|\mathrm{G}\left(y_{n}, y_{m}, y_{l}\right)\right| \leq\left|\mathrm{G}\left(y_{n}, y_{m}, y_{m}\right)\right|+$ $\left|\mathrm{G}\left(y_{l}, y_{m}, y_{m}\right)\right|$

Taking limit as $\mathrm{n}, \mathrm{m}, l \rightarrow \infty$, we get $\left|\mathrm{G}\left(y_{n}, y_{m}, y_{l}\right)\right| \rightarrow 0$ i.e., $\mathrm{G}\left(y_{n}, y_{m}, y_{l}\right) \rightarrow 0$. So $\left\{y_{n}\right\}$ is complex valued G-Cauchy sequence. Since either $S(X)$ or $T(X)$ is complete. Without loss of generality, we assume that $\mathrm{T}(\mathrm{X})$ is complete subspace of $X$, then the subsequence of $\left\{y_{n}\right\}$ must get a limit in $\mathrm{T}(\mathrm{X})$ (say) $\mathrm{z}$. Then $\mathrm{Tu}=\mathrm{z}$ for some $\mathrm{u} \in \mathrm{X}$, as $\left\{y_{n}\right\}$ is a complex valued G-Cauchy sequence containing a convergent subsequence, therefore the sequence $\left\{y_{n}\right\}$ also convergent implying thereby the convergence of subsequence of the convergent sequence. Next we show that $\mathrm{Su}=\mathrm{z}$. On setting $\mathrm{x}=\mathrm{u}, \mathrm{y}=x_{n}$ and $\mathrm{z}=x_{n}$, in (2.3), we have

$$
\mathrm{G}\left(S u, S x_{n}, S x_{n}\right) \preccurlyeq \mathrm{kG}\left(T u, T x_{n}, T x_{n}\right)
$$

Taking limit as $\mathrm{n} \rightarrow \infty$, we have $\mathrm{G}(S u, z, z) \precsim \mathrm{kG}(T u, z, z)$

Therefore, $|\mathrm{G}(S u, z, z)| \leq k|\mathrm{G}(\mathrm{Tu}, z, z)|$ implies that $\mathrm{Su}=\mathrm{z}$.

Therefore, $\mathrm{Su}=\mathrm{Tu}=\mathrm{z}$. i.e., $\mathrm{u}$ is coincidence point of $\mathrm{S}$ and $\mathrm{T}$. Since $\mathrm{S}$ and $\mathrm{T}$ are weakly compatible, it follows that $\mathrm{STu}=$ TSu i.e., $\mathrm{Sz}=\mathrm{Tz}$.

We now show that $\mathrm{Sz}=\mathrm{z}$. Suppose that $\mathrm{S}(\mathrm{z}) \neq \mathrm{z}$, therefore $0 \prec$ $\mathrm{G}(S z, z, z)$ implies that $|\mathrm{G}(S z, z, z)|>0$.

Putting $\mathrm{x}=\mathrm{z}, \mathrm{y}=\mathrm{u}, \mathrm{z}=\mathrm{u}$ in (2.3), we have

$\mathrm{G}(S z, S u, S u) \lesssim \mathrm{kG}(T z, T u, T u)=\mathrm{kG}(\mathrm{Sz}, \mathrm{z}, \mathrm{z})$

i.e., $|\mathrm{G}(S z, z, z)| \leq k|\mathrm{G}(S z, z, z)|<|\mathrm{G}(S z, z, z)|$ which is a contradiction, therefore

$\mathrm{Sz}=\mathrm{z}$. Thus $\mathrm{Sz}=\mathrm{Tz}=\mathrm{z}$ i.e., $\mathrm{z}$ is a common fixed point of $\mathrm{S}$ and $\mathrm{T}$.

Uniqueness: To prove uniqueness, suppose that $\mathrm{w} \neq \mathrm{z}$ be another common fixed point of $\mathrm{S}$ and $\mathrm{T}$. Then $0<$ $\mathrm{G}(z, w, w)$ implies that $|\mathrm{G}(z, w, w)|>0$.

Putting $\mathrm{x}=\mathrm{z}, \mathrm{y}=\mathrm{u}, \mathrm{z}=\mathrm{u}$ in (2.3), we have
$\mathrm{G}(z, w, w)=G(S z, S w, S w) \precsim \mathrm{kG}(T z, T w, T w)=\mathrm{kG}(\mathrm{z}, \mathrm{w}$, w)

i.e., $|\mathrm{G}(z, w, w)| \leq k|\mathrm{G}(z, w, w)|<|\mathrm{G}(S z, z, z)|$, which is a contradiction, therefore

$\mathrm{z}=\mathrm{w}$. Thus $\mathrm{Sz}=\mathrm{Tz}=\mathrm{z}$ i.e., $\mathrm{z}$ is a unique common fixed point of $S$ and $T$.

Example 5.1. Let $\mathrm{X}=[-1,1]$ and let $\mathrm{G}: X \times X \times X \rightarrow \mathbb{C}$ be complex valued G-metric space defined as follows:

$\mathrm{G}(\mathrm{x}, \mathrm{y}, \mathrm{z})=|x-y|+|y-z|+|z-x|$, for all $\mathrm{x}, \mathrm{y}$, $\mathrm{z} \in \mathrm{X}$. Then $(\mathrm{X}, \mathrm{G})$ is complex valued G-metric space. Define $\mathrm{S}, \mathrm{T}: \mathrm{X} \rightarrow \mathrm{X}$ as $\mathrm{Sx}=\frac{x}{2}$ and $\mathrm{Tx}=\frac{x}{6}$.

Here we note that, (2.1) $\mathrm{S}(\mathrm{X}) \subseteq \mathrm{T}(\mathrm{X}),(2.2)$ Both $\mathrm{S}(\mathrm{X})$ and $\mathrm{T}(\mathrm{X})$ are complete,

(2.3) $\mathrm{G}(\mathrm{Sx}, \mathrm{Sy}, \mathrm{Sz}) \lesssim \mathrm{k} G(\mathrm{Tx}, \mathrm{Ty}, \mathrm{Tz})$ holds for all $\mathrm{x}, \mathrm{y}, \mathrm{z} \in$ $\mathrm{X}, 1 / 3 \leq \mathrm{k}<1,(2.4) \quad \mathrm{S}$ and $\mathrm{T}$ are weakly compatible because $\mathrm{S}$ and $\mathrm{T}$ commute at their coincidence point i.e., at $\mathrm{x}=0$ and $\mathrm{x}=0$ is the unique common fixed point of $\mathrm{S}$ and $\mathrm{T}$.

\section{REFERENCES}

[1] Azam, A Fisfer, B, Khan, M: Common fixed point theorems in complex valued metric Spaces. Number. Funct. Anal. Optim.. 32(3), 243-253 (2011).

[2] B.C. Dhage, Generalized metric spaces and mappings with fixed point, Bull. Calcutt Math. Soc.84 (1992), 329336.

[3] B. C. Dhage, " On generalized metric spaces and topological structure. II," Pure and applied Mathematika Sciences, Vol.40, no.1-2,pp.37-41,1994.

[4] B. C. Dhage, " A common fixed point principle in Dmetric spaces." Bulletin of the Calcutta Mathematical Society, vol. 91, no.6, pp. 475-480, 1999.

[5] B. C. Dhage, "Generalized metric spaces and topological structure I," Annalele Stintifice ale Universitatii Al.1 Cuza, vol. 46, no. 1, pp.3-24, 2000.

[6] Balbir Singh, Vishal Gupta and Sanjay Kumar, “ Contraction Principle in Complex valued G-metric spaces" Journal of Complex system (under communication).

[7] G. Jungck, Common fixed point for non continuous non self mappings on non metric Spaces, Far East J. Math.Sci. 4(2) (1996), 199-212.

[8] Z. Mustafa and B.Sims, Some remarks concering Dmetric spaces, Proceedings of International Conference on Fixed Point Theory and applications, Yokohama Publishers Valencia Spain, July 13-19(2004), 189-198.

[9] Z. Mustafa and B.Sims, A new approach to a generalised metric spaces, J. Nonlinear Convex Anal., 7(2006), 289297. 